\title{
Benzodiazepines were as safe as and more effective than placebo for out-of-hospital status epilepticus
}

\author{
Alldredge BK, Gelb AM, Isaacs SM, et al. A comparison of lorazepam, diazepam, and placebo for the treatment of \\ out-of-hospital status epilepticus. N Engl J Med 2001 Aug 30;345:631-7.
}

Source of funding: Health.

For correspondence: $\mathrm{Dr}$ D H Lowenstein, Harvard Medical School, Boston, $M A$ USA.

daniel_lowenstein@ hms.harvard.edu. National Institutes of

\section{QUESTION: In patients with out-of-hospital status epilepticus, are benzodiazepines safer and more effective than placebo when given by paramedics for terminating the condition?}

Design clinicians, data collectors, and outcome assessors $\}$ †,* placebo controlled trial with follow up to time of arrival at the emergency department.
Randomised \{allocation concealed*\}†, blinded \{patients,

Lorazepam (Lor) v diazepam (Dia) v placebo (Plac) for out of hospital status epilepticus until arrival at the emergency department $\$$

\begin{tabular}{lllll}
\multirow{2}{*}{$\begin{array}{l}\text { Outcome } \\
\text { Termination of status } \\
\text { epilepticus }\end{array}$} & $\begin{array}{l}\text { Comparisons } \\
\text { rates }\end{array}$ & RBI $(95 \% \mathrm{Cl})$ & NNT (Cl) \\
\cline { 2 - 5 } & Lor $v$ Dia & $59 \% v 43 \%$ & $37 \%(-13$ to 80$)$ & Not significant \\
\cline { 2 - 5 } & Lor $v$ Plac & $59 \% v 21 \%$ & $166 \%(60$ to 268$)$ & $3(2$ to 8$)$ \\
\hline Dia $v$ Plac & $43 \% v 21 \%$ & $80 \%(0$ to 190$)$ & $\begin{array}{l}\text { Borderline } \\
\text { significance }\end{array}$ \\
\hline
\end{tabular}

¥Abbreviations defined in glossary; RBI, NNT, and $\mathrm{Cl}$ calculated from adjusted data in article.

\section{COMMENTARY}

Convulsive status epilepticus (CSE) is a neurologic emergency. Prolonged CSE leads to brain damage and neurological morbidity and could also increase the risk for death. Furthermore, delaying treatment could result in CSE becoming more difficult to control. ${ }^{1}$ The study by Alldredge $e t$ al shows that out-of-hospital, intravenous administration of lorazepam and diazepam by paramedics is as safe as and more effective than placebo. Such early, out-of-hospital treatment is particularly important if the time to arrival at the emergency department is prolonged - a common scenario in clinical practice. $^{2}$

The study by Alldredge et al should help alleviate doubts about the safety of these intravenous drugs at commonly recommended dosages. Fewer cardiopulmonary complications occurred with benzodiazepines than with placebo, but groups did not differ statistically. Lorazepam, commonly preferred by clinicians because of its longer anticonvulsant effect, had more CSE terminations than did diazepam, but groups did not differ statistically.

Finally, the intervention was ineffective in about $40 \%$ of patients, a higher failure rate than previously reported. ${ }^{23}$ However, the definition of success in this study, termination of CSE at arrival in the emergency department, differs from previous studies.

In applying the study findings, 3 conditions should be met. First, patients should have good respiratory and haemodynamic function. A higher frequency of cardiorespiratory complications may occur in patients who are sicker than those in this study. Second, paramedics require training. Third, clinicians at participating emergency departments must actively support this out-of-hospital intervention.

Samuel Wiebe, MD, MSc University of Western Ontario, London, Ontario, Canada

1 Lowenstein DH, Alldredge BK. Status epilepticus at an urban public hospital in the 1980s. Neurology 1993;43:483-8.

2 Treiman DM, Meyers PD, Walton NY, et al. A comparison of four treatments for generalized convulsive status epilepticus. N Engl J Med 1998;339:792-8.

3 Leppik IE, Derivan AT, Homan RW, et al. Double-blind study of lorazepam and diazepam in status epilepticus. JAMA 1983;249:1452-4.
Setting

San Francisco, California, USA.

\section{Patients}

205 patients (258 enrollments) who were $\geqslant 18$ years of age (mean age $51 \mathrm{y}, 63 \%$ men, $50 \%$ white) and had an out-of-hospital diagnosis of status epilepticus. Exclusion criteria included pulse $<60$ beats/minute, systolic blood pressure $<100 \mathrm{~mm} \mathrm{Hg}$, and a history of long-term use of or sensitivity to benzodiazepines. Only data from the first enrollment of each patient was reported. \{Follow-up was 100\%.\}†

\section{Intervention}

Patients were allocated to intravenous injection of lorazepam, $2 \mathrm{mg}(\mathrm{n}=66)$; diazepam, $5 \mathrm{mg}(\mathrm{n}=68)$; or placebo $(n=71)$, given over a 1 to 2 minute period and only during generalised tonic clonic seizure activity. If seizures recurred or continued $\geqslant 4$ minutes after the first injection, an identical second injection was given. Open label diazepam was immediately available for a difficult or unsafe extrication of a patient or if a patient was at high risk for a life threatening complication.

\section{Main outcome measures}

Termination of status epilepticus and out-of-hospital complications.

\section{Main results}

\{Analysis was by intention to treat.\} $\uparrow$ Lorazepam and diazepam groups did not differ, but each were more effective than placebo for terminating status epilepticus (diazepam $v$ placebo comparison was of borderline statistical significance) (table). An out-of-hospital complication occurred in $11 \%, 10 \%$, and $23 \%$ of patients who received lorazepam, diazepam, and placebo $(\mathrm{p}=0.08)$, respectively.

\section{Conclusion}

In patients with status epilepticus, both lorazepam and diazepam were as safe as and more effective than placebo when given by paramedics for terminating the condition.

*See glossary.

$\dagger$ Information provided by author. 